\title{
Murilo Mendes: ciclone habitado
}

Maria Lúcia Wiltshire de Oliveira Universidade Federal Fluminense

Para avançar eu me volto sobre mim mesmo Ciclone pelo imóvel habitado.

Jean Tardieu'

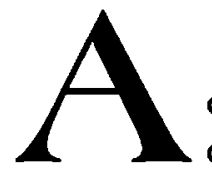

obra de Murilo Mendes (1901-1975) pocle ser compreendida a partir de fases progressivas ou de núcleos de orientação. O primeiro critério tende a considerar dois momentos, o da fantasia e o da construçâo, sem desprezar a tensĩo que se observa entre ambos e a presença de elementos formais e temáticos da fase inicial nos livros derradeiros. A outra vertente agrupa técnicas e temas, sem contudo livrar-se da progressão cronológica, identificando cinco núcleos, ${ }^{2}$ a saber: poemas modernistas parodisticos e de humor; poemas de ênfase surrealista; poemas de misticismo católico; poemas de fundo social e histórico; e poemas experimentais. Estudos mais recentes tendem a recusar a idéia segundo a qual a fase de construçâo seria superior a da fantasia. Com efeito, a extraordinária riqueza poética de $O$ Visionário, obra que reúne 62 poemas surrealistas escritos de 1930 a 1933, confirma este entendimento ao exibir exuberância imagética, forte plasticidade, tensão sonho/realidade e combinação insólita de elementos, justificando, de certo modo, o título do livro que atribui ao poeta uma dimensão profética. De toda forma, a crítica é unânime na identificação de dois grandes processos na poética

' Les Têmoins Invisibles, apud BACHELARD, [s.d.]. p. 159.

2 Segundo a visao de SANT"ANNA, In: MENDES, 1979. p. 159-60. 
muriliana: a busca de uma totalidade unificadora e a combinação de elementos dispares.

Neste trabalho tento mostrar, através da consideração de um poema da fase surrealista, como um texto de alta fragmentação angustiosa consegue expressar a ânsia de uma totalidade apaziguadora, dialetizando fantasia e construçào, multiplicidade e unidade. O poema - O sonbo é vida -, é o segundo do Livro Terceiro, p.108, de $O$ Visionário, editado em primeira edição pela José Olympio, em 1941. Além de ser o mais enigmático do conjunto, é o que mais se afina com o título da obra ${ }^{3}$ pois sua metáfora fundamental, o ciclone, como um duplo do poeta, consegue ver o futuro com uma força avassaladora e revigorante. Tal como fomos visionados há mais de meio século pelo poeta, somos agora os peregrinos ciclônicos da pós-modernidade, ameaçados pelo caos e igualmente tocados pela nostalgia da ordem. Eis o poema:

\section{O sonho é vida}

1 Ele nasceu ciclone e não sabia,

Por isso é que as constelaçōes, os braços, as pedras

Deixavam-no passar;

As virgens recuavam, as prostitutas também;

5 Os bancos, os quartéis, as usinas

Fechavam as janelas,

$O$ deserto mandava a esfinge na frente

Para lutar com ele;

Os arranha-céus cresciam para ele não alcançar;

10 As orquestras se refugiavam nas vitrolas,

Os anjos no céu, o demônio no inferno, os mortos no purgatório;

Até que ele um dia, cansado,

Apagou o último seio-farol na noite de pedra,

Trancou-se nos limbos

15 E encerrou com um sinal o ciclo dos tempos.

3 Também o desenho que ilustra a capa da edição de 1941 exibe imagens presentes no poema em análise (esfinges, deserto, farol). 
A publicação do poema na edição citada sugere uma disposição em duas estrofes, já que o espaço em branco entre o verso 11 e 12 é um pouco maior que a separação entre os demais versos. Em todos os seus estratos, o poema confirma esta dupla articulação, a começar pela escolha dos tempos verbais. Na segunda estrofe, os verbos no pretérito perfeito - "apagou", "trancou-se", "encerrou" - representam um ponto final para as ações, até então de caráter durativo na primeira estrofe com verbos no imperfeito como "deixavam", "recuavam", "mandava", etc. Assim, considerando-se a apresentação gráfica e a sintaxe verbal, o texto revela um movimento binário cujos agentes, por sua vez, se diferenciam. De um lado tem-se uma singularidade, um $e u$; de outro, uma multiplicidade, um mundo. Estas duas fontes de ação polarizam uma incompatibilidade, responsável pela tensão que percorre o texto.

Se no título do poema - O sonbo é vida - o tom sentencioso evoca a natureza visionária do poeta como profeta, no primeiro verso - Ele nasceu ciclone e não sabia - a dicção lembra a autoridade e a oralidade das narrativas arcaicas. Mas também se, por um lado, o tom é épico, de outro é dramático em razão da interdependência das partes e da tensão produzida entre elas. Um dos mistérios do poema reside na aparente desarticulação entre o corpo do texto e o seu título. $O$ aforismo do título lembra-nos dois grandes poetas, Baudelaire e Calderon de la Barca, para os quais vida e sonho eram realidades intercambiáveis. E se a cabeça do poema é metafisica e axiomática, o corpo, ao contrário, é imagético, plástico e concreto, estabelecendo-se aí um outro nivel de tensão. Neste as imagens representam um nâo-eu-o mundo-, de natureza substancial, enquanto que o eu-tratado como ele, o ciclone - é de feição aérea. Há um combate entre a identidade alada, imaterial, espiritúal $\mathrm{e}$ as identidades terrenas do plano material.

A imagem fundamental do poema - o ciclone - revela, antes de tudo, movimento. Se na concepção de Antônio Cândido, ${ }^{4}$ a terra,

\footnotetext{
4 Apud MOURA, 1991. p. 8.
} 
- mare o ar são as três grandes dimensões da poesia de Murilo Mendes, aqui verificamos um duelo entre a primeira e o último. Na materialização do imaginário muriliano, o ar é efetivamente um elemento poderoso. Ao estudar a imaginação do movimento, Bachelard relaciona a sublimação aérea a uma psicologia ascensional - "O convite à viagem aérea, se tiver, como convém, o sentido da subida, é sempre solidária da impressão de uma ligeira ascensão".s Se o imaginário do ar se liga a uma verticalidade, o movimento translacional do ciclone aponta para uma errância e um ex-centramento, enquanto sua ação rotacional responde pela circularidade permanente do ser. "E que espiral é o ser do homem!", exclama o filósofo. ${ }^{6}$

Na imagem acoplam-se, pois, três vetores cinéticos distintos, cada qual responsável por um certo movimento da alma humana. Em primeiro lugar, a rotação sobre si mesmo é signo da introversão, da viagem interior, da busca da "imensidão" íntima, da profundiclade sempre desejada e jamais alcançada em seu centro. Na imagem espiralada do ser não há um centro fixo, substancial, sólido e no próprio centro da espiral - metáfora do coração humano - o ser é errante e inalcançável. Na percepçāo dos limites da individualidade, revigora-se a noção de circuito ininterrupto onde "tudo é rodeio, discurso, tudo é uma romaria, tudo é refrão de estrofes sem fim".' Em segundo lugar, o movimento translacional retoma a idéia de errância no plano exterior, numa geografia ex-cêntrica pela qual o ser experimenta seus limites no mundo. E, por último, o movimento ascensional, de vôo para cima, acrescenta o desejo do Absoluto, que leva o ser para além da horizontalidade terrena.

A imagem ciclônica reinaugura a metafísica fantástica segundo a qual bomo no intelligendo fit omnia." Para longe da metafísica

' BACHELARD, 1990. p. 10.

6 BACHELARD, [s.d.]. p. 159.

' BACHELARD, [s.d.]. p. 159.

VICO, 1979. p. 89. 
racional e como toda metáfora poética, o ciclone é uma "fabulazinha minúscula"" que ilumina intuitivamente a natureza do mundo ou cla alma humana. Percebendo a sua própria angústia, furor, desejo de Absoluto, enfim, suas vicissitudes, o poeta conta a sua pequena história ao criar a metáfora, nela se transformando. O ciclone conjuga dialeticamente interioridade e exterioridade, rotação e translação, introversão e errância, verticalidade e horizontalidade, além de promover outras associações que dizem respeito à natureza humana.

Para Bachelard, no devaneio acordado próprio à intencionalidade poética, "toda imagem aérea tem um porvir, tem um vetor de vôo"." O vôo ciclônico do poeta, ao se configurar como uma viagem vertical e libertária, tem uma partida e uma chegada, uma origem no passado e um destino no futuro. Entre os dois limites, a navegação aérea se dá na dependência absoluta das imagens visuais, já que o vento é feito de nada. Sabemos que as imagens aéreas são as que melhor condizem com a operação do crescimento que caracteriza a vida espiritual. Certos poetas são marcados por esta verticalidacle "que engrandece e tonifica todos os seres no sentido da altura"." Em Assim falava Zaratustra, a concepção urânica de liberdade e alegria envolve o herói que busca nas alturas o frio e o ar para se reabastecer espiritualmente. Na solidão e no silêncio, sua poética reverte numa ética humana feita de leveza, espiritualidade, alegria e ausência de culpa. Também no poema muriliano, a leveza do ciclone se contrapõe ao peso dos objetos do mundo. Mas se o tom heróico do personagem nietzschiano ilustra uma vontade determinada, no ciclone a vontade forte se cansa, revelando o patético em seu esforço desenfreado. $\mathrm{Na}$ imagem do vento furioso, símbolo da cólera pura, reúnem-se as idéias de vontade e imaginação. "Ao viver intimamente as imagens do furacão - diz Bachelard - aprendemos o que é a vontade furiosa e vã". ${ }^{2}$ Embora dotado de vontade, o

\footnotetext{
9 VICO, 1979. p. 89.

"10 BACHELARD, 1990. p. 22.

" BACHELARD, 1990. p. 45.

"2 BACHELARD, 1990. p. 231.
} 
ciclone faz uma movimentação indisciplinada e desordenada em razão de sua inconsciência, inexperiência, ingenuidade ou inocência original - ele "não sabia" que era ciclone. Da exacerbação do esforço, inútil (?), resulta um ser "cansado".

A mistura de elementos soa heteróclita e dissonante, expressando o "hibridismo" do poeta, segundo Merquior, ${ }^{13}$ "o processo futurista da montagem e o processo surrealista da sequiência onírica", registrado por Bosi. ${ }^{14}$ Como ele próprio se "microdefine", o poeta exprime o mundo, escrevendo graças ao "não reconhecimento da fronteira realidade-irrealidade" e ao "dom de assimilar e fundir elementos dispares". ${ }^{15}$ Para começar, o segundo verso enumera substantivos incongruentes, apesar de claros e objetivos. São pedaços do mundo que, na dimensão onírica, metonimizam-no. Tem-se aí a conjunção do Ar (constelações) e da Terra (pedras), no meio dos quais vive o Ser (braços). No quarto verso, os semas virgens e prostitutas polarizam positiva $e$ negativamente a sexualidade feminina. Os elementos do quinto verso - bancos, quartéis, usinas - formam um conjunto com afinidades entre si, metonimizando instituições sociais, onde a opressão se acentua por serem espaços fechados cujos respiradores - as janelas - se cerram, em contraposição ao espaço aberto onde se move o ciclone.

Na benevolência (deixavam-no passar), no afastamento (recuavam) ou na recusa afrontosa (fechavam as janelas), ainda não se tornara explicita a agressividade dos versos seguintes: $O$ deserto mandava a esfinge na frente/ Para lutar com ele. Tem-se aqui uma atmosfera de guerra em que a esfinge ${ }^{16}$ desempenha um papel de

\footnotetext{
is Apud MOURA, 1991. p. 8.

" BOSI, 1974. p. 499.

"MENDES, 1979. p. 13.

${ }^{16}$ A imagem da esfinge aparece na obra do poeta em outros lugares, como no poema "Descanso": Brinco facilmente com as esfinges (Apud MOURA, 1991. p. 111).
} 
ataque. Quando contemplado, o deserto é paradoxalmente inquietante e apaziguador. Se sua imagem silencia e aplaca a intimidade atormentada pela sugestão de imensidão que dele absorvemos, também o seu despojamento, a sua esterilidade e a sua ausência de vida reforçam a sensação de vazio íntimo que nos arrasta para um sentimento de desumanização. Alegoria da humanidade desvitalizada e espiritualmente estéril, o deserto do poema é habitado por uma entidade bélica e inumana, feita de cabeça e peito de mulher, garras de leão, corpo de cão, cauda de dragão e asas de pássaro que devora os que não lhes decifram os enigmas. $\mathrm{Na}$ lenda labdácida, Édipo decifra o enigma ao mesmo tempo em que sela o seu futuro desventuroso. No poema, quem enfrenta a esfinge é o ciclone, novo Édipo a perseguir o seu destino. Como o ciclone, o herói tebano nasceu Édipo (= pés inchados, por decisão dos pais) e não sabia. Na inconsciência de sua verdadeira origem, vagou e lutou, até que um dia apagou o seu olhar para o mundo, cegando-se, exilando-se e encerrando uma dinastia amaldiçoada. Se Édipo pôde ser ciclônico, não somos nós herdeiros do seu heroísmo trágico (e mesmo quixotesco) a viver entre o Céu e a Terra tentando desvendar, inutilmente, o enigma da existência? No centro, pois, do poema ( $v .7$ e 8), é travada a luta entre um mundo enigmático, representado pela esfinge, e o herói perplexo.

Nos versos seguintes convivem, absurdamente, conjuntos semânticos opostos: o cotidiano profano e o atemporal sagrado. De um lado, arranba-cétus, orquestras, vitrolas, marcas da modernidade brasileira emergente, responsáveis também pela datação do poema. De outro, os elementos teológicos anjos, demônios, mortos, cếu, inferno, purgatório que ultrapassam a cronologia terrena. No entanto, ambos os conjuntos rejeitam qualquer proximidade com o herói. Da arte de estabelecer relações entre tais elementos díspares obtém-se um novo efeito ou uma nova realidade, qual seja, a da inexistência de fronteiras entre o físico e o moral, entre o tempo histórico e a eternidade. A justaposição, no entanto, não é regida pelo automatismo psíquico, como recomendavam os surrealistas de primeiro momento, mas ditada por um projeto maior em que o 
Fragmento aponta para o Todo, revelando que o Múltiplo é a prova da existência do Uno. A fusão do tempo histórico (das orquestras, arranba-céus, vitrolas) com o tempo escatológico (dos anjos, demônios e purgatório) ilustra a busca de uma Totalidade que efetive a síntese de todos os elementos dissonantes.

A segunda estrofe, de quatro versos, representa a cessação do movimento ascensional, rotacional e translacional do eu-ciclônico. Lembra o momento em que os ventos se aplacam e a bonança sobrevêm à tempestade. Recorda também o período do sono onde vigora uma outra vida - a do sonho - muito semelhante à da morte. Estabelece-se a noite em oposição ao dia, o descanso em substituição à errância. Imagens herméticas como seio-farol e noite de pedra nos arrastam, respectivamente, ao mito de Édipo, já mencionado, e ao de Sísifo no que tange ao esforço vão e ao cansaço do ciclone.

No sintagma noite de pedra, o sema pedra tem valor diferente do usado no verso segundo. Investigando-o em outros poemas de $O$ Visionário, verificamos que ora ele representa o elemento terra como lugar de descanso ("Até as ondas possuem / Uma pedra para descansar a cabeça"17), ora como fragmento do mundo ("O mundo se desfaz em pedra"18); pode sugerir também resistência do ser frente ao mundo ("Meu coração l...] tem / Uns pedacinhos de pedra / Que resistem duramente"19), ou ainda um obstáculo ao ser ("Quem foi que colocou / Uma pedra no meu sonho" ${ }^{20}$ ). Não é nosso objetivo fazer a fenomenologia da pedra na obra de Murilo Mendes, mas partindo do ideal de estabilidade atribuído por Bachelard ao elemento pedra/rocbedo,

\footnotetext{
17 MENDES, 1941. p. 113.

${ }^{18}$ MENDES, 1941. p. 113.

1" MENDES, 1941. p. 121.

${ }^{20}$ MENDES, 1941. p. 74.
} 
O rochedo é assim uma imagem primordial, um ser da literatura ativa, da literatura ativista que nos ensina a viver o real em todas as suas profundidacles e prolixidades. ${ }^{21}$

percebemos na expressão noile de pedra não só o mais profundo

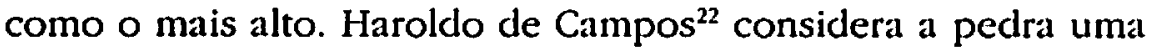
metáfora do rigor na poética muriliana, representando força $e$ contenção. No poema em causa, o ciclone parece regressar à noite de pedra como forma de recolher para aquele locus a sua força dispersa e ali se concentrar, nos limites de sua invisibilidade, até ao final dos tempos (Juízo Final?) e a chegada de um novo dia ou Tempo onde se dê o início de um novo ciclo dos tempos (Ressurreição dos Mortos?). A positividade desta estrofe é o contraponto da negatividade da estrofe anterior, anunciando uma moral cósmica que pode premiar os esforços e a coragem do herói frente às adversidades do mundo.

A ressonância edipiana retorna na imagem materno-fálica seio-farol que justapõe o elemento feminino (seio /mãe/ terra/ horizontalidade) ao masculino (farol /falo /céu /verticalidade). Ao apagar este estranho objeto, simultaneamente protetor e orientador, o eu-lírico abdica da racionaliclade viril (farol = "luz da razão") como da emocionalidade protetora (seio). Abrindo mão cle sua ascendência, de seu passado, o poeta fica só, patética ou triunfalmente só. Mergulha na noite onde todas as formas e seres se eqüivalem. Ao tempo em que produz o não-ser, a imagem evoca a indiscriminada e desejada totalidade dos tempos primordiais.

O sema limbos, do verso seguinte, renova a isotopia do transcendente e do sagrado. Como um espaço insaturado de culpa, reservado aos inocentes pagãos, destina-se àqueles que, embora marcados pelo pecado original, não respondem por sua exclusão da comunidade católica. Pluralizado no poema, o limbo perde sua aura religiosa, banalizando-se. Graças à sua ambivalência, aponta

\footnotetext{
21 BACHELARD, 1991 . p. 153.

22 CAMPOS, 1970. p. 60-1.
} 
para o lugar "aquém do bem e do mal" próprio aos que ainda não nasceram. Voltamos, pois, à questão da origem e da inocência aberta no primeiro verso - Ele nasceu ciclone e não sabia.

O verso final - E encerrou com um sinal o ciclo dos temposfecha o poema, completa o movimento do herói e encerra o ciclo dos tempos. Retoma-se o caráter profético-oracular do título e do primeiro verso. O determinismo escatológico é absorvido e transformado. Sinal torna-se aceno, gesto, perdendo, pois, conotações infaustas. O sema ciclo garante a idéia de permanência, de retorno, de sucessão, enfim, de ausência de finalização sombria. Assim, o poema se inicia e se conclui por esta isotopia da circularidade, tanto no plano individual, cristalizada na forma e na fenomenologia do ciclone, quanto no plano cósmico pela concepção cíclica dos tempos. Ambos apontam para a finitude paradoxal: o ciclone encerra sua errância e suspende o movimento da História. Passa-se do temporal ao atemporal, do móvel ao imóvel, da finitude à eternidade.

$\mathrm{Na}$ imagem do ciclone condensam-se, portanto, uma trajetória, uma história, uma fábula vivida por um herói. Seguindo a lição de Vico, podemos dizer que o ciclone é um universal fantástico, mais do que uma simples metáfora ou figura de similitude entre um tipo de vento e o Ser do homem, pois nele não se completa um termo ${ }^{23}$ ou sentido final. Tal como O cacto, de Manuel Bandeira, magnificamente lido por David Arrigucci, ${ }^{24}$ o ciclone de Murilo Mendes é um objeto natural que, tornado metáfora, ganha o sentido e a paixão projetados pela atividade imaginante. Ao sair do reino físico da natureza, o ciclone invade o universo da cultura, inaugurando o drama e expressando o conflito.

Entre tantas possibilidades, o poema enseja a leitura da antinomia natureza vs. cultura. De um lado está o ciclone a

${ }^{23} \mathrm{O}$ deus Termo (Terminus) representa ofim da polissemia pois de-termina o que é cada coisa.

${ }^{24}$ Apud anotações de aula em curso de Pós-graduação na FFLCH/USP no $2^{\circ}$ semestre/92. 
representar as forças naturais, a pureza das origens, a mítica do nascimento. De outro, está o mundo na sua artificialidade. Há uma tensão entre espontaneidade e reflexão cujo desenlace se dá na estrofe final. A espontaneidade diz respeito ao conceito de ingênuo, de Schiller, cuja idéia de integração original eu-mundo (ou sujeitoobjeto) está presente na raiz etimológica do termo, em português (in-gênuo) que remete para origem (do latim genesis) e em francês (naif) que aponta para nascimento e natural. A falta de consciência do personagem ciclônico expressa esse modo de o poeta sentir o mundo. O seu percurso é aberto e sua trajetória, irrefletida, intuitiva. Frente a ele, os substratos culturais são sujeitos de enunciados. No entanto, na imagem esfingica, inicia-se um processo de re-flexão, de dobra sobre si mesmo, de auto-conhecimento, de recorte de subjetividade, que carateriza o modo sentimental de sentir a realidade. Na resposta a ser dada ao enigma mítico, figura o reconhecimento da especificidade do humano e sua separação em relação ao mundo natural. ${ }^{25}$

Segundo a concepção schilleriana de gênero, "o poeta (...) ou é natureza ou a buscará. No primeiro caso, constitui-se o poeta ingênuo; no segundo, o poeta sentimental". ${ }^{26}$ No projeto da espiritualidade moderna, a infinitude, seja a da natureza, seja a da infância onto e filogenética, é passível de recuperação pela via da imaginação. Se a cisão é incontornável, resta ao poeta valer-se da fantasia para reunificar aquilo que no passado estava harmoniosamente unido no cosmo. No ciclone muriliano encontra-se este ideal de recomposição da memória. Numa leitura metalingüística, ele ć a cristalização da fantasia poética, única forma capaz de resgatar o passado, confirmando as palavras do poeta de que "a poesia começou no instante da criação do mundo, continua no plano temporal e se completará um dia na eternidade".

2s "Homem", era a resposta correta ao enigma "Qual é o animal que, de manbà, tem quatro pés, dois ao meio dia, e três à tarde?"

26 SCHILLLER, 1991. p. 60. 
A maneira elegiaca de sentir a vida, sub-gênero do sentimental, fica no limite entre o trágico e o patético. A solidão trágica do ciclone na primeira estrofe se modifica na segunda pela possibilidade de um novo Tempo em substituição aos tempos. Fazendo a fenomenologia de dois estados anímicos, o texto passa do épico-trágico para o épico-patético, processo em que a renúncia ao excesso anterior e a entrada numa ordem severa promovem o agenciamento da contenção apolínea com a tentativa sublime de reparação de uma dignidade ofendida, movida pelo patbos.

Por outro lado, caos é uma palavra-chave para designar a articulação espacial do poema. Nas mitologias e cosmogonias préfilosóficas, significa o vazio obscuro e ilimitado que precede e propicia a geração do mundo, mas também remete à desordem. Assim a expressão pode ser aplicada tanto ao lugar desordenado por onde circula o ciclone, quanto ao lugar donde ele vem e para onde ele se refugia. Diz Bachelard que o caos é uma representação da interioridade e - acrescentamos -, de uma interioridade agitada ou pacificada. O poema marcha do movimento para o repouso, do conflito para a solução.

O ritmo também é duplo no poema. Na primeira estrofe, à exceção do verso inicial, a sintaxe é acelerada pela ausência de conectivos e pela enumeração de imagens sucessivas. $O$ ritmo é presto. $\mathrm{Na}$ segunda estrofe, há mudança de andamento, que de rápido vai se tornando moderado e lento até o adágio do último verso, iniciado pela conjunção " $\mathrm{E}$ ". Também a princípio o verso é mais prosaico transbordando da linha poética (pelo menos na mancha tipográfica da $1^{1 !}$ edição) para depois ganhar contenção e sublimidade.

Feita a análise, chegamos a duas interpretações, no mínimo. Uma é simbólica, centrada na morte definitiva e na negatividade; outra é figural ou alegórico-figural ${ }^{27}$ remetendo-se ao quadro teológico cristão, onde a morte é provisória.

${ }^{27} \mathrm{O}$ conceito é de AUERBACH, 1942. 
No desenvolvimento da primeira hipótese, o ciclone é um particular que revela o universal. Trata-se do homem em seu destino inelutável. Nesta leitura pagã, a uma bybris (expansão), segue-se o métron (contenção), configurando-se uma tragédia com início, meio e fim que vai do desequilibrio/vida ao equilibrio/morte. Renunciar à expansão do ser eqüivale então a suprimir o sujeito e operar a sua reintegração ao todo. Tal como na estética do "poema em prosa", a morte se assemelha ao transe, à vidência, ao sonho. Se a morte é sonho e se a vida é morte, é no sonho/morte que a vida se faz mais real. Logo, o título do poema - O sonbo é vida - se articula com o último verso em que a morte é vida.

Se na estrofe inicial a oscilação se faz entre sujeito e objeto, na segunda o pêndulo oscila entre a vida e a morte, vencendo esta como forma de cessação do conflito e retorno ao equilíbrio. A demanda do Absoluto revela a nostalgia de reintegração com o Todo e, portanto, significa a recusa da separação eu-mundo. Logo, ao narrar sua própria morte, o sujeito narra a sua reintegração à Natureza e se firma como não-ser. Ao dizer ele nasceu ciclone, está dito ele nasceu poeta ou ele nasceu vidente, já que os três predicativos se eqüivalem. Movimentando-se num espaço que não é o céu nem a terra, ${ }^{24}$ o ciclone habita um reino. Seria o pontificado da Poesia? Estariamos diante de um metapoema?

Numa outra interpretação, regida pela alegoria teológica, o ciclone fala (do grego agourein) de um outro (do grego allós) homem, inserido num determinado plano da criação: o divino. De raiz neoplatônica, esta leitura destaca o imaginário da dificuldade e da mortificação terrena que antecede a morte, vivida como descanso e passagem para o Eterno. Assim, o ciclone, pós-figurando Cristo, é a alegoria do homem que, pela ascese (do grego, combate), alcança a totalidade e a reinserção no plano divino.

23 Tanto na mitologia (COMMELIN, 1972. p. 112) quanto na meteorologia, os ventos, incluindo os ciclones, nào circulam nas alturas celestiais, regiào reservada aos deuses e aos astros. Encontram-se numa regiāo abaixo, junto às nuvens e nas vizinhanças da terra. 
Diante das duas possibilidades interpretativas, cabe ao leitor escolher entre a celebração das exéquias ou a homologação da esperança. É provável que também o autor tenha oscilado entre as duas alternativas.

Em resumo, buscamos mostrar que a estrutura do poema se revela binária em várias dimensões: na estrofação, no ritmo, na sintaxe e na imagética. A existência de dois pólos em tensão, a começar pela forma conceptual do título em contraposiçào à forma substantiva do corpo, expressa a alternância peculiar do poeta entre objetivismo e essencialismo. O conjunto das imagens potencializa oposições, como sagrado vs. profano, temporal vs. eternidade, concreto vs. abstrato, matéria vs. espírito. No plano espacial há o jogo entre verticalidade/horizontalidade, aberto/fechado, ar/terra, alto/baixo. Quanto ao movimento, a oscilação se dá entre expansão e contenção, entre errância e repouso. Considerando-se os sujeitos das ações, há um $e u$ anteposto ao mundo, uma parte desprendida de um todo. A singularidade deste $e u$ alterna-se entre dois estados de ânimo - apolíneo e dionisíaco -, duas atuações - trágica e patética - e duas predisposições de espírito - a inconsciência e a determinação. No espaço do lírico, o poeta dialetiza o épico e o dramático, confirmando o pensamento de Schiller de que os gêneros são antes de tudo formas de sentir o mundo.

Nossa leitura registrou a presença de um ser nostálgico em busca da totalidade perdida, o que nos conduziu a uma dupla interpretação. A primeira está melancolicamente centrada na negatividade do não-ser, cujo apanágio é a morte irremediável; a segunda está voltada para a esperançosa positividade do por-vir, na expectativa silenciosa de outra vida após a morte. De uma forma ou de outra, reitera-se o fundamento da poética muriliana de que o Múltiplo confirma o Uno.

Por fim, atribuímos à categoria da circularidade a responsabilidade pela dialetização de todas as antinomias. O ciclone a concretiza não só na dimensão fenomenológica da imagem, como também na materialidade do signo, pois o ciclo do último verso está contido no ciclone do primeiro verso. Lembrando-nos por fim da 
milenar serpente que morde a própria cauda, ícone da articulação entre vida e saber, revimos a conjunção de fantasia e construção num poema de teor surrealista, que anuncia a fase seguinte de Murilo Mendes pela possibilidade de re ligação com o divino, promessa final da Religião.

\section{Referências Bibliográficas}

BACHELARD, Gaston. A poética do espaço. Rio de Janeiro: Eldorado Tijuca, [s.d.].

BACHELARD, Gaston. O are os sonhos. Så Paulo: Martins Fontes, 1990.

BOSI, Alfredo. História concisa da literalura brasileira. 2. ed. São Paulo: Cultrix, 1974.

CAMPOS,Haroldo. Murilo e o mundo substantivo. In: Metalinguagem. 2. ed. Petrópolis: Vozes, 1970.

COMMELIN, P. Nova mitologia. Rio de Janeiro: Ediçð̄es de Ouro, 1972.

MENDES, Murilo. O Visionário. Rjo de Janeiro: José Olympio, 1941.

MENDES, Murilo. O menino experimental; antologia. Org. Affonso Romano de Sant'Anna. São Paulo: Summus, 1979.

MERQUIOR, José Guilherme. Arte e sociedade em Marcuse, Adomo e Benjamin. Rio de Janeiro: Tempo Brasileiro, 1969.

MOURA, Murilo Marcondes de. Murilo Mendes: a poesia como totalidade. 1991. Dissertação (Mestrado) - FFLCH/USP, São Paulo, 1991.

SCHILLER, Friedrich. Poesia ingênula e sentimental. São Paulo: lluminuras, 1991.

VICO, Giambattista. Principios de uma ciência nova; acerca da natureza comum das naçỏes. 2. ed. Sel. trad. e notas Antônio Lázaro de Almeida. São Paulo: Abril Cultural, 1979. 


\section{Resumo}

Através da análise de um poema de Murilo Mendes, reencontramos a nostalgin de um ser em relaçào à totalidade perdida. Em todos os estratos da análise, há dois pólos em tensào, evidenciando a alternância típica do poeta, sobretudo na primeira fase, entre objetivismo e essencialismo. A estruturaçăo binária se manifesta no ritmo, na sintaxe, na imagética, no estado de ânimo e na estrofaçāo. Entre o ingênuo e o sentimental, entre a natureza e a cultura, entre o épico e o dramático, enfim, entre a negatividade do nâo-ser e a positividade do por-vir, o poema reitern um dos fundamentos da poética muriliana: o muíltiplo como confirmaçào do uno. Dialetizando estes contrários, a imagem do ciclone os potencializa num movimento de circularidade, articulando vida e saber e re-ligando o humano ao divino.

\section{Résumé}

Dans notre analyse d'un poème de Murilo Mendes, nous retrouvons la nostalgie d'un être en mpport avec la totalité perdue. Partout les strates du texte, il y a une polarisation qui démontre l'alternation propre à ce poète, surtout dans sa première fase, entre la matière et l'essence. La structure binaire se révèle par le rithme, la sintaxe, les images, l'état animique et la disposition des strophes. Entre le naiff e le sentimental, entre la nature et la culture, entre l'épique et le dramatique, enfin, entre la positivité et la negativité, le poème confirme l'un des fondements de ce auteur: le multiple comme affirmation de l'un. En mettant les contraires en dialectique, l'image du cyclone les rendre force dans un mouvement de circularité où la vie se lie au savoir et l'humain au divin. 